\title{
The Role of Biomimetic Incubation of Sandblasted Titanium Implants in the Process of Osseointegration: An Experimental Study in Dogs
}

\author{
Nigmon L. Khabilov, PhD, ScD; Timur V. Melkumyan, PhD, ScD*; \\ Tatyana O. Mun; Farkhod K. Usmonov; Iskander M. Baybekov, PhD, ScD \\ Tashkent State Dental Institute \\ Tashkent, Uzbekistan
}

\begin{abstract}
The aim of the present study was to examine the surface characteristics and values of removal torque of an implant surface subjected to sandblasting with $125 \mu \mathrm{m} \mathrm{Al}_{2} \mathrm{O}_{3}$ particles with a following immersion in biomimetic fluid and to compare that surface with a machined implant surface.

Study protocol: Forty-eight conical implants were initially made of second-grade titanium alloy. The diameter of implants was $4 \mathrm{~mm}$ at the head and 2.6 at the apex, all implants were of $8 \mathrm{~mm}$ length and of large variable thread design. Half of them were subjected to sand blasting and immersion in biomimetic fluid at $37^{\circ} \mathrm{C}$ for four weeks with daily replenishment of solution until the moment of placement; another 24 implants were left with untreated machined surface. Three-dimensional roughness values were obtained with the help of confocal laser scanning microscope.

Forty-eight implants were implanted in 12 dogs. Twenty-four implants were retrieved after a 6-week healing period following installation, and the remaining 24 were removed upon the completion of 16 weeks, using a torque calibrator ((BTG150CN-S TOHNICHI) with a $20 \mathrm{cN} \cdot \mathrm{m}-150 \mathrm{cN} \cdot \mathrm{m}$ scale of force registration was applied for the measurements of the removal torque.

Results: The mean 3-dimensional roughness value of biomimetically treated implant surfaces was $1.34 \pm 0.24 \mu \mathrm{m}$ and the mean roughness value measured for the machined surfaces was $0.33 \pm 0.04 \mu \mathrm{m}(P<0.05)$. As to the average parameters of maximum peak-trough distance, these were equal to 2.85 for machined and 24.25 for incubated sandblasted implants. Machined implants demonstrated $49.5 \pm 10.3$ removal torque values after the 6-week healing period. But for the immersed sandblasted implants the same parameter was equal to $72.7 \pm 15.98 \mathrm{cN} \cdot \mathrm{m}$. During a 16 -week recovery period, these values increased up to $77.5 \pm 15.16 \mathrm{cN} \cdot \mathrm{m}$ and $89.7 \pm 11.83 \mathrm{cN} \cdot \mathrm{m}$ for machined and biomimetically treated sandblasted implants, respectively, $P<0.05$.

Conclusion: The present study demonstrated the rapid recovery time for biomimetically incubated sandblasted dental implants in comparison to machined surface implants based on findings of early (6 weeks healing period) removal tests. Although there was established only a $13.4 \%$ difference in values of removal torque after a 16 -week healing period (instead of $32 \%$ after 6 weeks of recovery) between two groups of implants which could be associated with delayed bone integration.
\end{abstract}

Keywords: dental implants; surface treatment; biomimetic fluid; roughness; removal torque.

\section{Introduction}

Currently, the use of threaded titanium implants with different types of osseoconducive rough surfaces is considered a conservative treatment modality for partially and fully edentulous patients [1]. Clinical experience of successful application of machined dental implants with a smooth surface texture has a history of about 50 years [2]. However,

*Corresponding author: Timur V. Melkumyan, PhD, ScD. Tashkent State Dental Institute. Tashkent, Uzbekistan. E-mail: t.dadamov@gmail.com the shortcomings of the first generation of implants associated with a long recovery period, the demands of patients who want to have their teeth sooner, and achievements of scientific research in this field have made it possible to introduce a dental product of higher quality which could meet the needs of doctors and patients.

The surface chemical composition of titanium implants is among the most important quality characteristics. A secondgeneration manufacturing process of dental implants means an application of physical and chemical factors, such as temperature, machining, sand blasting, anodization, sputtering, coating, acid etching, laser treatment, and sterilization. All of 
these are a source of ion, metal, lubricant and other kinds of contamination, which usually have a negative influence on successful osseointegration. That is why careful control of the chemical composition of the titanium implant surface in the manufacture of high quality dental products is of paramount concern [3-5].

One of the methods of titanium surface treatment which could avoid the consequences associated with the presence of chemical impurities in dental implants was suggested by Kokubo and co-workers and was called the biomimetic treatment [6,7]. Biomimetic deposition of microelements onto surfaces of titanium implant materials is a time consuming technique in the manufacture of implants. This method may take several weeks but allows hydroxyapatite and other calcium phosphate molecules to be deposited on the surfaces with complex geometry in a simulated body fluid solution under physiological conditions of temperature and $\mathrm{pH}$ [8-11]. As to the methods of examination, one of the most valuable quality tests of bone-to-implant integration cited frequently in the scientific literature is the determination of removal torque. Usually this type of biomechanical investigation is carried out in the course of an experimental animal study. Rabbit and dog tibias are the most frequently used bone sites for performance of such investigations $[12,13]$.

The aim of the present study was to examine the surface characteristics and values of removal torque of an implant surface subjected to sandblasting with $125 \mu \mathrm{m} \mathrm{Al}_{2} \mathrm{O}_{3}$ particles with a following immersion in biomimetic fluid and to compare that surface with a machined implant surface.

\section{Material and Methods}

Forty-eight conical implants were initially made of second-grade titanium alloy with the following chemical composition: Fe $\max -0.15$; $\mathrm{C} \max -0.05$; $\mathrm{Si} \max -0.08$; $\mathrm{N} \max -0.04$; Ti $\min -99.6$; O $\max -0.1$; $\mathrm{H} \max -0.008$. The diameter of implants was $4 \mathrm{~mm}$ at the head and 2.6 at the apex, all implants were of $8 \mathrm{~mm}$ length and of large variable thread design. Half of them were subjected to sand blasting and immersion in biomimetic fluid at $37^{\circ} \mathrm{C}$ for four weeks with daily replenishment of solution until the moment of placement; another 24 implants were left with untreated machined surface.

Simulated body fluid solution was prepared by dissolving reagent-grade $\mathrm{NaCl}, \mathrm{NaHCO} 3, \mathrm{KCl}, \mathrm{Na} 2 \mathrm{HPO} 4 \cdot 7 \mathrm{H} 2 \mathrm{O}$, $\mathrm{MgCl} 2 \cdot 6 \mathrm{H} 2 \mathrm{O}, \mathrm{CaCl} 2$ and $\mathrm{NaSo} 4$ in distilled water containing buffering agent, $\mathrm{HCl}$ and $(\mathrm{CH} 2 \mathrm{OH}) 3 \mathrm{CNH} 2$ at $\mathrm{pH} 7.25$.

Roughness values were evaluated in accordance with recommendations established by Albrektsson \& Wennerberg. Commercially pure titanium plates were used as initial material to obtain the abovementioned parameters. The samples were made of the same titanium grade material and were rectangular in shape $(5 \times 8)$.

Mean roughness $(\mathrm{Sa})$ and maximum peak-trough distance (St) were measured with the help of an Aristoplan confocal laser-scanning microscope (Leica, Germany). Measurements were made using a 20x eyepiece under vertical resolution less than $20 \mathrm{~nm}$. For separation of waviness, the profile roughness calculations were made with a Gaussian filter. Applied cut-off values $(\lambda c)$ were $0.8 \mathrm{~mm}$ and $0.25 \mathrm{~mm}$.

\section{Animals}

Twelve dogs were selected for the study. Experiments were performed in the experimental center of Tashkent Medical Academy. The procedures in this study were performed in accordance with the National Institutes of Health Guide for the Care and Use of Laboratory Animals. Maximal effort was made to minimize animal trauma and the number of animals necessary for the acquisition of reliable data. All experiments were approved by our local ethics committee.

All surgical stages associated with implant insertion and assessments of removal torque were carried out under general anesthesia with rometar $2 \mathrm{mg} / \mathrm{kg}$ and $0.5 \mathrm{ml}$ atropine; maintenance with novocaine $2 \%$ local infiltration. Postoperative care protocol included penicillin $G$ and nonsteroidal anti-inflammatory drugs for 5 days. The selected site of implantation was the internal part of the animal's tibia. In each limb we inserted two implants (four implants in every animal): one machined surface implant was placed in the proximal epiphysis of the dog's tibia, and one sand blasted implant immersed in biomimetic fluid was placed in the distal epiphysis of the same tibia. Incisions were made in appropriate locations with a split thickness flap technique. Drillings were made under cool physiological saline irrigation. After insertion of an implant into the prepared bed, the periosteum was sutured with chromic gut 3/0, and nylon 3/0 was applied for the skin.

The second surgical steps took place 6 and 16 weeks later. After administration of general anesthesia to the animals, incisions were made again in the implant zones and the heads of 24 implants (12 machined and 12 incubated sand blasted) were exposed. After 16 weeks the same procedure was carried out with the remaining 24 implants.

In both study intervals, after removing the locking screws, the torque gauge (BTG150CN-S TOHNICHI) with a $20 \mathrm{cN} \cdot \mathrm{m}-150 \mathrm{cN} \cdot \mathrm{m}$ scale of force registration was applied for the measurements of the removal torque.

Results were statistically processed using the software package Statistica 6.1. A probability value of $P<0.05$ was considered statistically significant.

\section{Results and Discussion}

The mean 3-dimensional roughness value of biomimetically treated implant surfaces was $1.34 \pm 0.24 \mu \mathrm{m}$ and the mean roughness value measured for the machined surfaces was $0.33 \pm 0.04 \mu \mathrm{m}(P<0.05)$. As to the average parameters of maximum peak-trough distance, these were equal to 2.85 for machined and 24.25 for incubated sandblasted implants.

Machined implants demonstrated $49.5 \pm 10.3$ removal torque values after the 6 -week healing period. But for the immersed sandblasted implants the same parameter was equal to $72.7 \pm 15.98 \mathrm{cN} \cdot \mathrm{m}$. During a 16 -week recovery period, these values increased up to $77.5 \pm 15.16 \mathrm{cN} \cdot \mathrm{m}$ and $89.7 \pm 11.83$ $\mathrm{cN} \cdot \mathrm{m}$ for machined and biomimetically treated sandblasted implants, respectively, $P<0.05$. 
Implant surfaces are the subject of prolonged studies in order to reach the fastest and safest clinical consolidation of artificial root abutments. At present, machined or firstgeneration implant surfaces clearly have been surpassed by newer second-generation ones. Sandblasting procedures with or without etching (Tioblast and SLA surfaces), anodic oxidation (TiUnite surface by Nobel Biocare), laser modified micro- and nano-structured surface (Brånemark BioHelix Implant), calcium phosphate coated implants, plasma spraying, sputter-deposition, and biomimetic precipitation are techniques for which several authors should be given a special mention $[2-5,14]$.

Numerous in vitro studies confirmed that the topographical surface characteristics of titanium implants influence blood clot retention, protein adsorption, platelet adhesion, degree of tissue inflammation, osteogenic cell response, and finally the rate of healing [15-18]. It has been already established that the gingival tissue and bone marrow cell response could be considerably influenced by the chemical composition of the implant surfaces [19-21].

Therefore, biomimetically produced titanium implant surfaces may be useful in facilitating early bone ingrowth into porous surfaces without the possibility of fibrous tissue encapsulation and eventual coating failure, which may occur with other types of titanium implant surface manufacturing processes because of the presence of chemical impurities.

\section{Conclusion}

The present study demonstrated the rapid recovery time for biomimetically incubated sandblasted dental implants in comparison to machined surface implants based on findings of early (6 weeks healing period) removal tests. Although there was established only a $13.4 \%$ difference in values of removal torque after a 16-week healing period (instead of 32\% after 6 weeks of recovery) between two groups of implants which could be associated with delayed bone integration.

\section{Competing interests}

The authors declare that they have no competing interests.

\section{References}

1. Chandra R, Bains R, Loomba K, Pal US, Ram H, Bains VK. Endosseous dental implant vis-à-vis conservative management: Is it a dilemma? Natl J Maxillofac Surg 2010; 1(1):26-9.

2. Abraham CM. A brief historical perspective on dental implants, their surface coatings and treatments. Open Dent J 2014; 8:50-5.

3. Löberg J, Mattisson I, Hansson S, Ahlberg E. Characterisation of titanium dental implants I: Critical assessment of surface roughness parameters. Open Biomat J 2010; (2):18-35.

4. Albrektsson T, Wennerberg A. Oral implant surfaces: Part 1-- review focusing on topographic and chemical properties of different surfaces and in vivo responses to them. Int $\mathrm{J}$
Prosthodont 2004; 17(5):536-43.

5. Albrektsson T, Wennerberg A. Oral implant surfaces: Part 2-- review focusing on clinical knowledge of different surfaces. Int J Prosthodont 2004; 17(5):544-64.

6. Kokubo T, Takadama H. How useful is SBF in predicting in vivo bone bioactivity? Biomaterials 2006; 27(15):2907-15. 7. Loty C, Sautier JM, Boulekbache H, Kokubo T, Kim HM, Forest N. In vitro bone formation on a bonelike apatite layer prepared by a biomimetic process on a bioactive glassceramic. J Biomed Mater Res 2000; 49(4):423-34.

8. Kim HW, Kim HE, Salih, V. Stimulation of osteoblast responses to biomimetic nanocomposites of gelatinhydroxyapatite for tissue engineering scaffolds. Biomaterials 2005; 26(25):5221-30.

9. Liu YL, de Groot, K, Hunziker EB. Biomimetic mineral coatings in dental and orthopaedic implantology. Front Mater Sci (China) 2009; 3:154-62.

10. Vidigal GM Jr, Groisman M, de Sena LA, Soares Gde A. Surface characterization of dental implants coated with hydroxyapatite by plasma spray and biomimetic process. Implant Dent 2009; 18(4):353-61.

11. Jonášová L, Müller FA, Helebrant A, Strnad J, Greil P. Biomimetic apatite formation on chemically treated titanium. Biomaterials 2004: 25(7-8):1187-94.

12. Klokkevold PR, Johnson P, Dadgostari S, Caputo A, Davies JE, Nishimura RD. Early endosseous integration enhanced by dual acid etching of titamium: a torque removal study in the rabbit. Clin Oral Impl Res 2001; 12(4):350-7.

13. Hohlt WF. Ask us. How to remove an osseointegrated palatal implant. Am J Orthod Dentofacial Orthop 2004; 126(3):19A.

14. Liu XY, Chu PK, Ding CX. Surface modification of titanium, titanium alloys, and related materials for biomedical applications. Mater Sci Eng R-Rep 2004; 47(3-4):49-121.

15. MacDonald DE, Rapuano BE, Deo N, Stranick M, Somasundaran P, Boskey AL. Thermal and chemical modification of titanium-aluminum-vanadium implant materials: effects on surface properties, glycoprotein adsorption, and MG63 cell attachment. Biomaterials 2004; 25(16):3135-46.

16. Massaro C, Rotolo P, de Riccardis F, Milella E, Napoli A, Wieland $\mathrm{M}$, et al. Comparative investigation of the surface properties of comercial titanium dental implants. Part I: chemical composition. J Mater Sci Mater Med 2002; 13(6):536-48. 17. Cordioli G, Majzoub Z, Piatelli A, Scarano A. Removal torque and histomorphometric investigation of 4 different titanium surfaces: An experimental study in the rabbit tibia. Int J Oral Maxillofac Implants 2000; 15(5):668-74.

18. Park JY, Davies JE. Red blood cell and platelet interactions with titanium implant surfaces. Clin Oral Implants Res 2000; 11(6):530-9.

19. Masaki C, Schneider GB, Zaharias R, Seabold D, Stanford C. Effects of implant surface microtopography on osteoblast gene expression. Clin Oral Implants Res 2005; 16(6):650-6. 20. Tan KS, Qian L, Rosado R, Flood PM, Cooper LF. The role of titanium surface topography on J774A.1 macrophage inflammatory cytokines and nitric oxide production. Biomaterials 2006; 27(30):5170-7.

21. Anselme K, Linez P, Bigerelle M, Le Maguer D, Le Maguer A, Hardouin P, et al. The relative influence of the topography and chemistry of TiAl6V4 surfaces on osteoblastic cell behavior. Biomaterials 2000; 21(15):1567- 77. 